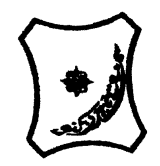

Bayero Journal of Pure and Applied Sciences, 12(2): 191 - 196

Received: October, 2019

Accepted: December, 2019

ISSN $2006-6996$

\title{
KNOWLEDGE AND PRACTICE OF QUALITY ASSURANCE PROGRAMME OF X- RAY EQUIPMENT AMONG RADIOGRAPHERS IN KANO METROPOLIS
}

\author{
*Sidi, M. and Bello, A.A \\ Department of Medical Radiography, Bayero University Kano \\ *Corresponding author: msidi.radg@buk.edu.ng, +2348039264238
}

\begin{abstract}
The main goal of quality assurance programme is to consistently provide diagnostic information at the lowest possible cost, and at the least possible exposure of the patient to ionizing radiation. The study aims at evaluating the knowledge and practice of quality assurance programme on X-ray equipment among radiographers in Kano metropolis. The study design was prospective and cross sectional conducted among radiographers in the Kano metropolis from April 2019 to October 2019. Non-probability sampling method was used in the selection of the respondents. An ethical clearance to conduct the study was obtained from the Human Research and Ethics Committee of the Kano State Ministry of Health, and informed consent was obtained from every selected respondent. A structured questionnaire was designed and used an instrument for data collection. The questionnaire was validated by experienced colleagues, using a pilot study the reliability was rested and the chronbach's alpha reliability coefficient was found to be 0.76 . Forty one questionnaires were administered to the consented radiographers in Kano metropolis. The obtained data was analyzed using SPSS version 22.0. Out of the 41 (100\%) administered questionnaires $36(87 \%)$ were returned, and all the returned questionnaires were properly filled. Only 3 (8.3\%) known the meaning of quality assurance programme, only 12 (33.3\%) know the components of quality assurance programme and only 6 (16.7\%) know the frequency of computed radiography system quality control tests. The average score for knowledge among radiographers in Kano metropolis is $44.9 \%$ and that of practice is $47.9 \%$. The study concludes that radiographers in Kano metropolis have poor knowledge and pactice of quality assurance programme.
\end{abstract}

Keywords: Knowledge, quality assurance, Kano metropolis, Radiographers and X-ray equipment

\section{INTRODUCTION}

Quality assurance (QA) programme in diagnostic radiology is defined as "an organized effort by the staff operating facility to ensure that the diagnostic images produced are of sufficiently high quality so that they consistently provide diagnostic information at the lowest possible cost, and at the least possible exposure of the patient to ionizing radiation (WHO, 1984). The nature and extent of this programme will vary with the size and type of the facility, the type of examinations conduand other factors. The determination of what constitutes high quality in any QA programme will be made by the diagnostic radiology facility producing the images (Stephen et al., 2012). The quality assurance program encompasses quality control technique and quality administration procedures. Quality control technique deals with instrumentation and equipment, whereas quality administration procedures involve management actions that guarantees proper performance and evaluation of monitoring technique, as well as ensuring that required corrective actions are taken in response to monitoring results (Sidi et al., 2014).

The utilization of a variety of $\mathrm{x}$-ray equipments for diagnostic procedure has been in practice for over a long period of time, which makes their maintenance and their test of quality assurance be of paramount importance in ensuring their effectiveness (Atomic Energy Regulatory Board Mumbai, 2016).. The equipments involve in measuring quality assurance include; multiometer, al filter tissue equivalent phantom and survey meter, the quality control test performs in these equipments are; processor quality control test, repeat-reject analysis, quality control test for computed tomography scanner, imaging plate for computed radiography, detector calibration digital radiography, mean glandular dose for mammography machine, performance parameters for digital subtraction angiography as well as fluoroscopic image quality parameters (Atomic Energy Regulatory Board Mumbai, 
BAJOPAS Volume 12 Number 2, December, 2019 2016). The QC tests of the equipments are done routinely to optimize their functional performance and ensure they are comparable to their baseline values and also in accordance with the tolerance values as specified by a regulatory body. The personals responsible for quality control tests include; radiographers, quality assurance technologist, service engineer and medical physicist. However, the quality control tests that are within the limit of radiographers and technologist should be reviewed by medical physicist.

Radiographers are the end users of X-ray equipment; therefore it is of paramount important for them to have a good knowledge and practice of quality assurance programme for optimal operation of the equipment. They carry out the day-to-day QC tests on the equipment as prescribed by the QC test schedule, record and/or chart the QC test, measurement data, evaluate the test results, report any deterioration or trends in equipment performance to the radiology management (Périard \& Chaloner, 1996). Studies conducted by Rahimi et al. (2019) in Iran; Ofori et al. (2013) in Ghana both reported poor implementation of quality assurance programme. Furthermore, a study conducted by Sidi, (2018) reported poor knowledge and practice of quality control tests for computed tomography scanners among radiographers in the northwest Nigeria. However, to the best knowledge of the researchers' there is no documented work on knowledge and practice of quality assurance programme of general X-ray equipment among radiographers in Kano metropolis. The findings of the study will serve as a baseline for making recommendations to the relevant authorities and also serve as a guide to the radiographers. The study aims at evaluating the knowledge and practice of quality assurance programme on Xray equipment among radiographers in Kano metropolis.

\section{MATERIALS AND METHODS}

The study design was prospective and cross sectional conducted among radiographers in the Kano metropolis from April 2019 to October 2019. Non-probability sampling method was used in the selection of the respondents. An ethical clearance to conduct the study was obtained from the Human Research and Ethics Committee of the Kano State Ministry of Health (MOH/Off/797/T.I/1457), and informed consent was obtained from every selected respondent. A structured questionnaire was designed and used an instrument for data collection. It consist of three section; A, B and C; section $A$ is the demographic information on the respondents, section B contains questions on knowledge of quality assurance programme, and section $\mathrm{C}$ on practice of quality assurance programme. The questionnaire was validated by experienced colleagues, using a pilot study the reliability was rested and the chronbach's alpha reliability coefficient was found to be 0.76 . Forty one questionnaires were administered to the consented radiographers in Kano metropolis. The knowledge and practiced will be considered poor if the average score is less than $50 \%$, or good when the average score is $50 \%$ and above. The obtained data was analyzed using SPSS version 22.0.

\section{RESULTS}

Out of the $41 \quad(100 \%)$ administered questionnaires $36(87 \%)$ were returned, and all the returned questionnaires were properly filled.

\section{Frequency}

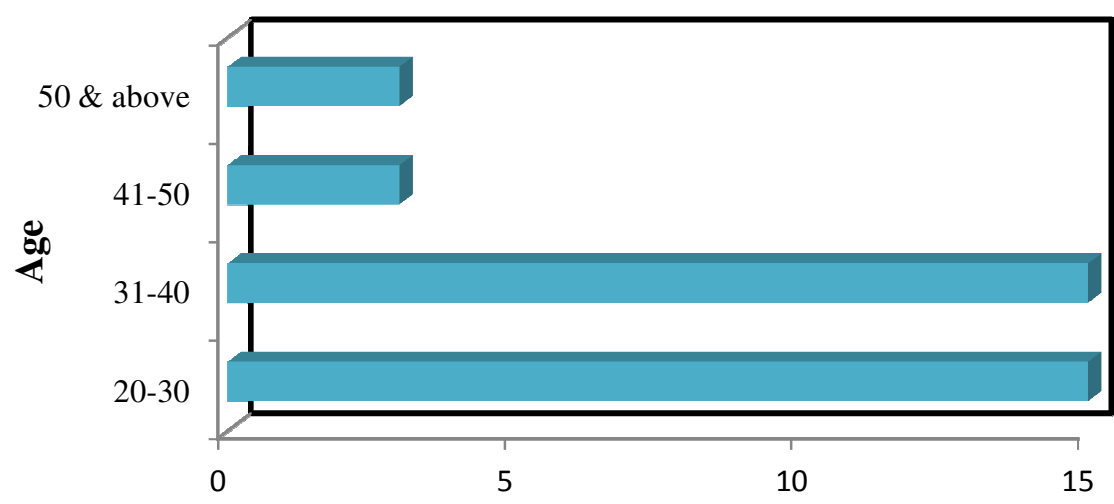

Figure 1: Age of the Respondents

Figure 1 shows the age class of the respondents, the highest frequency of respondents was seen in age class of 20-30 years and $31-40$ years, followed by $41-50$ years and above 50 years with the same frequency. 


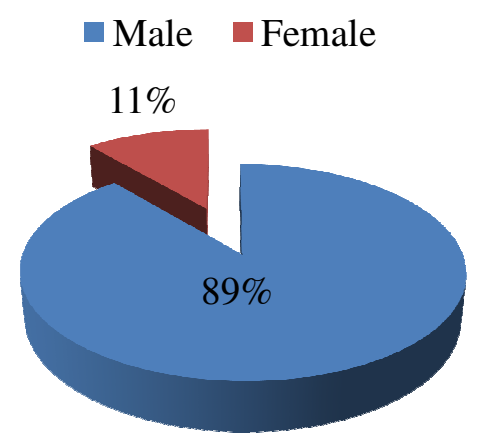

Figure 2: Gender of the Respondents

Figure 2 shows the gender of the respondents; $89 \%$ were males while $11 \%$ were females.

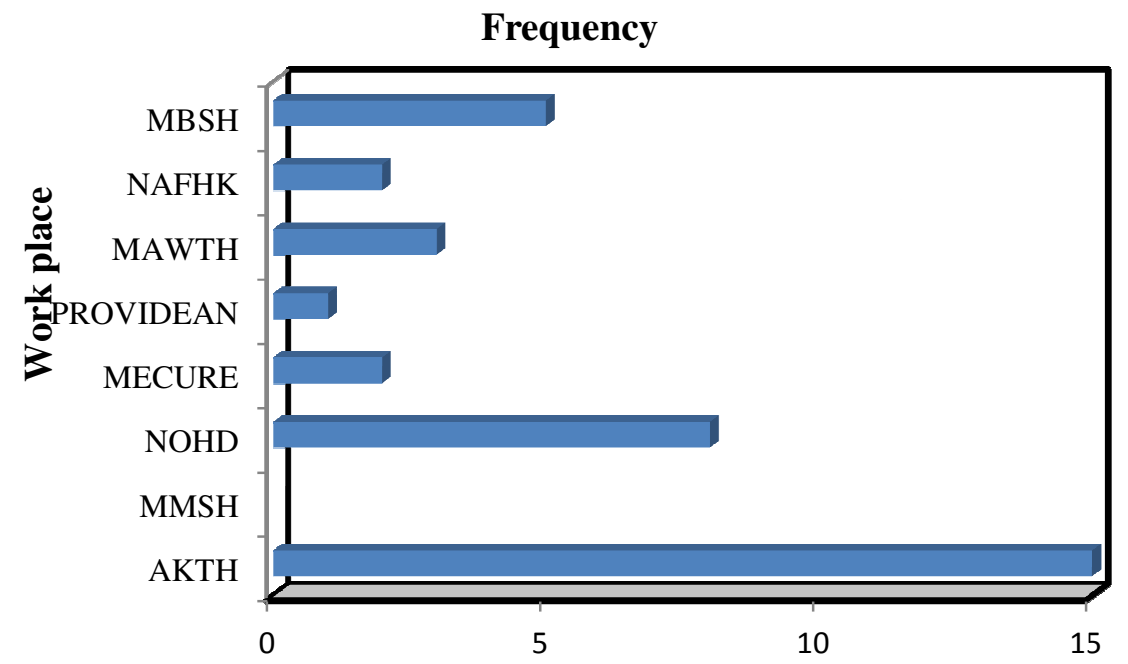

Figure 3: Workplace of the Respondents

**Aminu Kano Teaching Hospital (AKTH)

**Murtala Mohammed Specialist Hospital (MMSH)

$* *$ National Orthopedic Hospital Dala (NOHD)

**Mohammad Abdullahi Wase Teaching Hospital (MAWTH)

**Nigerian Air force Hospital Kano (NAFHK)

**Mohammadu Buhari Specialist Hospital (MBSH)

Figure 3 shows the work place of the respondents; Aminu Kano Teaching Hospital had the highest number of the respondents followed by National Orthopedic Hospital Dala. Providian had the lowest number of respondents.

$$
\square \text { B.Rad } \square \mathrm{MSc} \quad \mathrm{PhD}
$$

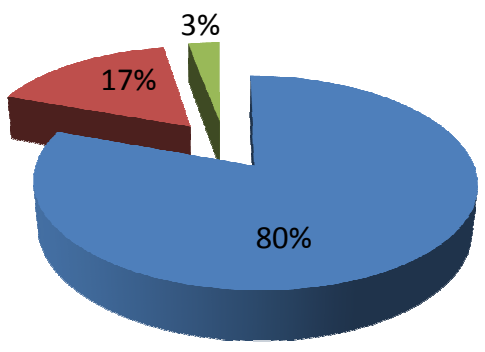

Figure 4: Qualification of the Respondents

Figure 4 shows the qualification of the respondents; $80 \%$ had B. Rad, $17 \%$ had M. Sc and 3\% had Ph.D. 


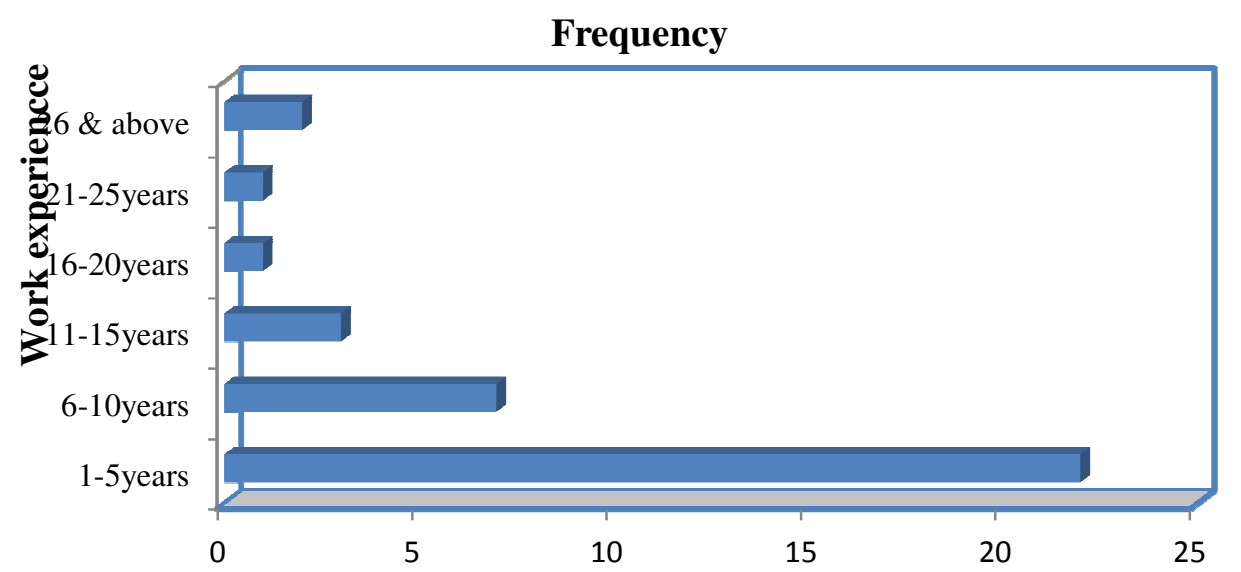

Figure 5: Work experience of the Respondents

Figure 5 shows the work experience of the respondents; 1-5 years work experience had the highest frequency followed by respondents with 6-10 years work experience. Respondents with 16-20 years and $21-25$ years had the lowest frequency.

Table 1 shows the knowledge of quality assurance among radiographers in Kano metropolis Table I: Knowledge of quality assurance

\begin{tabular}{lcc}
\multicolumn{1}{c}{ Questions } & Answers \\
\cline { 2 - 3 } & Frequency & (\%) \\
\hline $\begin{array}{l}\text { Q6. Quality assurance programme refers to? } \\
\text { Q7. Do you consider patient dose reduction as one of the aims of }\end{array}$ & 3.3 \\
quality assurance programme? & 35 & 97.2 \\
Q8. Quality assurance programme consist of & 12 & 33.3 \\
Q9. What is the frequency of processor quality control test? & 10 & 27.8 \\
Q10. What is the frequency of reject/repeat film analysis? & 9 & 25.0 \\
Q11. Quality control test for fluoroscopy unit include the following & 25 & 69.4 \\
Q12. Is phantom used in quality control test for fluoroscopy equipment? & 18 & 50.0 \\
Q13. Which of the following is a daily quality control test for CT scanners? & 26 & 72.2 \\
Q14. Phantom is used in all the following quality control test except & 21 & 58.3 \\
Q15. What is the frequency of computed radiography systems & 6 & 16.7 \\
$\quad$ quality control test? & 19 & Q16. \\
Detector calibration using flat field test is a weekly quality control & 52.8 \\
for digital radiography system? & 10 \\
Q17. For mammography machines, the mean glandular dose should be checked & 27.8 \\
Q18. Performance parameters for digital subtraction angiography systems which & 16 & 44.4 \\
are related to image quality and which can be evaluated with a non-invasive & & \\
phantom are the following & &
\end{tabular}

Table 2 shows the practice of quality assurance among radiographers in Kano metropolis

Table 2: Practice of quality assurance

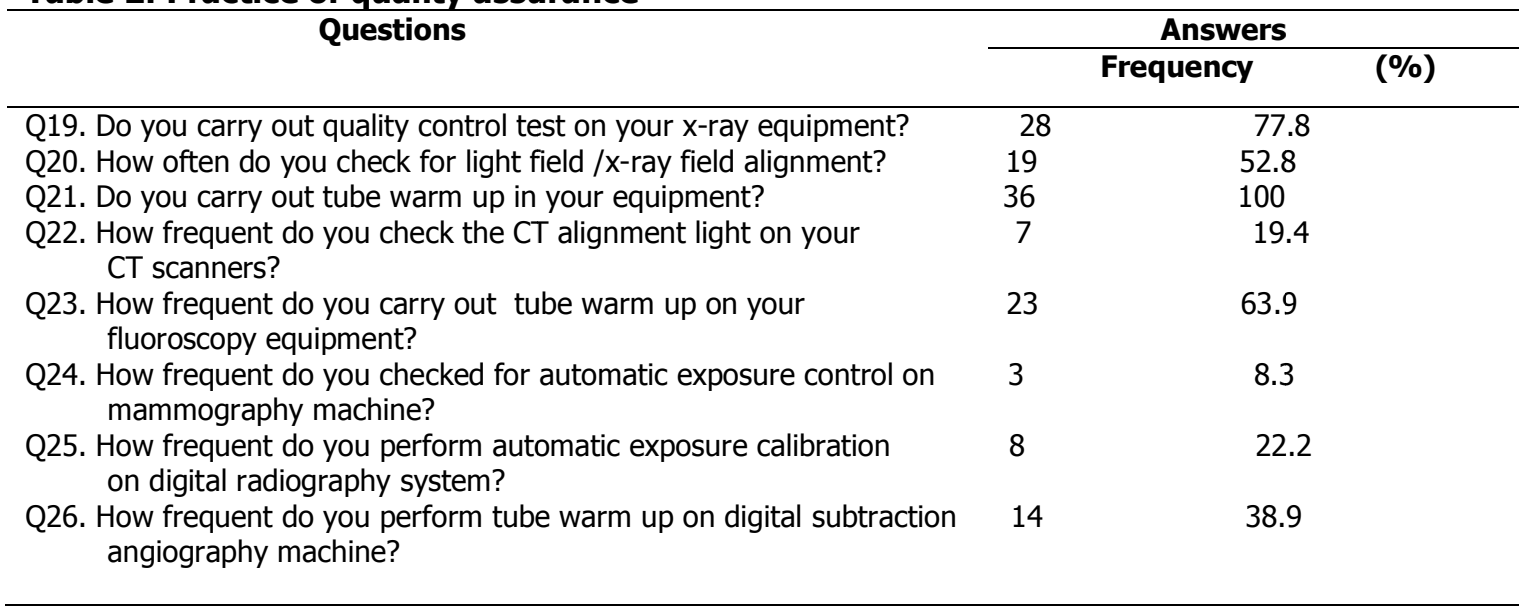


BAJOPAS Volume 12 Number 2, December, 2019 DISCUSSION

The findings of the study show that only 3 $(8.3 \%)$ of the respondents know the meaning of the quality assurance programme as shown in Table 1 above. All radiographers ought to have known what quality assurance programme is all about due to its role in the production of quality diagnostic images, minimizing running cost of the facility and reducing radiation dose to patients, staffs and other members of the public. The results of the study revealed that 35 $(97.2 \%)$ of the respondents are aware of the patient dose reduction as one of the aims of the quality assurance programme as shown in Table 1 above. Therefore, convincing radiographers in Kano metropolis to facilitate quality assurance programme will not be difficult because they have known its link with patient radiation dose. Only 12 (33.3\%) of radiographers have known quality assurance programme consist of quality control technique and quality administration procedure as shown in Table 1 above. To have effective quality assurance programme radiographers should know the components of the programme, the compositions of each component and the responsibilities of each component. The findings of the current study show that only $10(27.8 \%)$ of the respondents are familiar with the frequency of the processor quality control test as indicated in table I above. Processor quality control tests is one of the daily quality control tests perform; therefore every radiographer has to know the daily quality control tests and how its perform. The findings of the study also show that only $9(25 \%)$ of the respondents have known the frequency of reject/repeat film analysis as shown in Table 1 above. Reject/repeat film analysis is an important quality control test usually performed by radiographers; therefore, every radiographer ought to have known the frequency at which the test should be performed. The results of the study show that $25(69.4 \%)$ of the respondents know quality control test, perform on fluoroscopy equipment, and 18 (50\%) of the respondents said yes phantom is used in quality control test for fluoroscopy machine as shown in Table 1. Therefore, fluoroscopic equipment is expected to have a long life span because the radiographers handling is familiar with the quality control test. Also the result of current study shows that $26(72.2 \%)$ of the respondents are familiar with the daily quality control test for CT scanners as indicated in Table 1 above. The findings are contrary to the findings of the study conducted by Sidi, (2017) on assessment of knowledge and practice of quality control test for computed tomography scanners among radiographers in northwest Nigeria that reported only $24.5 \%$ knew daily quality control test for computed tomography scanners. This is an indication of improvement of knowledge of quality control test for computed tomography scanners in Kano metropolis.

The findings of the study show that 21 (58.3\%) of the respondents know phantom is used in the following quality control test which are CT number accuracy, image noise and image uniformity, but only (6) $16.7 \%$ of the respondents have known the frequency of computed radiography system quality control test as shown in Table 1 . This shows that majority of the radiographers in Kano metropolis are not conducting quality control test on computed radiography, and by implication this will affect the life span of the equipment.

The results of the study also show that 19 $(52.8 \%)$ of the radiographers identify that detector calibration using flat field test is a weekly quality control test for digital radiography system as indicated on Table 1 above. Despite the fact that digital radiography is new in the study area but the majority of radiographers have known the weekly quality control test of the equipment, and this will have positive effect on the life span of the equipment.

Also the findings of the study show that only 10 (27.8\%) of the respondents have known that for mammography machines the mean glandular dose should be checked quarterly as shown in Table 1 . This is a very important quality control test because of the high sensitivity of the breast tissue to ionizing radiation. Only $16(44.4 \%)$ of the respondents identify spatial resolution, low contrast performance, contrast and spatial uniformity and subtraction artifacts are performance parameters for digital subtraction angiography systems which are related to image quality and which can be evaluated with non invasive phantom. The radiographers handling angiographic equipment ought to have known the tests because of the effect on image quality. Furthermore the findings of the study show that $28(77.8 \%)$ of the respondents said they carry quality control test on their equipments practice as shown in Table 2 above. Nineteen (52.8\%) of the respondents practice light field / $\mathrm{x}$-ray field alignment test on their equipment as shown in Table 2 above. This is a quality control test that is within the limit of radiographers; it minimizes repeat rate, hence reduces running costs and radiation dose. The results of the study show that $36(100 \%)$ of the radiographers carries out tube warm-up on their equipment as indicated on Table 2 above. Only 7 (19.4\%) of the respondents practice $\mathrm{CT}$ alignment light tests on their scanners as shown on Table 2 above. 
BAJOPAS Volume 12 Number 2, December, 2019

This test is very important in localization of anatomical structure in the human body more especially in CT guided biopsy. Therefore, since most of the radiographers did not practice the test to ensure the accuracy of the equipment; there is a great tendency to miss-locate anatomical structure during CT guided biopsy. The results of the study show that 23 (63.9\%) of the respondents practice tube warm-up on their fluoroscopy equipment. The good practice of tube warm-up among the respondents in both conventional $X$ - ray and fluoroscopic units will have a positive impact on the life span of the equipment. Only $3(8.3 \%)$ of respondents checked for automatic exposure control on mammography machine, and only $8(22.2 \%)$ of the respondents perform automatic exposure control calibration on digital radiography machine. However the findings from the current study show that only (38.9\%) carry out tube warm-up on digital subtraction angiography machine. Automatic exposure control regulates

\section{REFERENCES}

Atomic Energy Regulatory Board Mumbai (2016). Available https://www.aerb.gov.in/english/. [Accessed 18 $8^{\text {th }}$ June, 2019]

Ofori, Eric, Antwi, William K, Scutt, Diane (2013) Current status of quality assurance in diagnostic imaging departments in Ghana. The South African Radiographer, 51 (2): 19-25

Périard, M. A., \& Paul. Chaloner. (1996). Diagnostic X-Ray Imaging Quality Assurance: An Overview. Available from: https://www.canada.ca/content/dam/hc -sc/migration/hc-sc/ewhsemt/alt formats/hecssesc/pdf/pubs/radiation/qualityassurance art-qualite/assuranceeng.pdf. [Accessed 15 $5^{\text {th }}$ July, 2019]

Rahimi, S. A., Babakeshizade, M., Mohammadi, K., \& Mahmoudi, R. (2019). Quality Assurance in Diagnostic Radiology: Current Status and Desirable Situation. CPQ Medicine, 5(2), 01-10. the exposure time which has a direct link with the dose of radiation patient received during exposure.

Furthermore, findings from the study revealed that the respondents have poor knowledge of quality assurance programme on $\mathrm{x}$-ray equipments having $44.9 \%$ of the overall score. Also, findings from the study show a poor level of practice $(47.9 \%)$ among the respondents. With the increasing number of clinical applications and high radiation dose associated with $x$-ray equipments, it is of great concern to know that the majority of the respondents scored less than $50 \%$ on average on questions of knowledge and practice of quality assurance programme. Smooth operational performance of $x$-ray equipments could only be achieved with effective quality assurance practices and accurate results from quality assurance practices could only be achieved with a good knowledge of quality assurance programme.

Sidi, Mohammed. (2018). Assessment of Knowledge and Practices of Quality Assurance Tests for Computed Tomography among Radiographers in North-West of Nigeria. Nigerian Journal of Medical Imaging and Radiation Therapy, 6 (1): 6-11

Sidi, M., Abba, M., Nwobi, C., \& Dare, A. (2014). Assessment of Quality Assurance Programs for Conventional X-Ray Equipment in Kano Metropolis. Journal of the Association of Radiographers of Nigeria; 28 (1); 28 (1): 19-24

Stephen I, Cyril S, Geoffrey E John F (2012). Quality Assurance and Quality Control in Diagnostic Radiology Practice-The Ghanaian Experience, Wide Spectra of Quality Control, InTech,. Available from: http://www. intechopen.com [Accessed $20^{\text {th }}$ September, 2019]

World Health Organization (WHO) Geneva (1984), Quality Assurance in Diagnostic Radiology, Available from: https://apps.who.int/iris/handle/10665/4 0423. [Accessed $12^{\text {th }}$ July 2019] 